\title{
Effect of rs2241766T $>$ G polymorphism in Adiponectin Gene on Circulating Adiponectin Levels among Iraqi Women with PCOS
}

\author{
Rasha Shaker Nima \\ Department of Chemistry, College of Science, University of Kufa
}

\begin{abstract}
Background: Polycystic ovary syndrome (PCOS) is a most common endocrine /metabolic disorder of women in their reproductive ages. Although PCOS is complex, but there is strong evidence that candidate genes on insulin action have been proposed to show a vital role in its etiology. Aim:The current research was designed to study the effect of (rs2241766T $>$ G)in adiponectin gene with PCOS, and their impact on the level of serum adiponectinand insulin resistance (HOMA-IR) in Iraqi women with PCOS. Methods: The case -control design study was performed on 120 women with and without PCOS. Phenotypic analysis included the estimation of fasting levels of; blood glucose, and lipid profile by spectrophotometric methods, while insulin, and adiponectin concentrations were determined by ELISA. Genotyping of the selected $S N P(r s 2241766 T>G)$ in the adiponectin gene was carried out by (PCR-RFLP) technique. Results: After controlling for the age, body mass index, significant difference in Waist circumferences, fasting insulin, HOMA-IR, and serum adiponectin levels were found in POCS group with respects to those of a healthy control group. Genotyping and alleles results of the selected SNP (rs2241766T $>G)$ were not associated with incident of PCOS. However, women with PCOS with TG and GG genotype had higher insulin levels, and HOMA-IR than carriers of the TTgenotype. Conclusions: The current study point out that the selected SNP (rs2241766T>G) in adiponectin gene is not relatedto PCOS in Iraqi women. Nevertheless, the selected polymorphism was found to be associated with insulin levels, and HOMA-IR among Iraqi women with PCOS, and to impact adiponectin secretion.Further research with a greater sample size, and more SNPs in adiponectin gene are wanting to confirm these results.
\end{abstract}

Keywords: Polycystic ovary syndrome,genotyping,serum adiponectin,adiponectin gene, SNPs.

\section{Introduction}

Polycystic ovarian syndrome is one of the most common endocrine/metabolic syndrome of women in their reproductive age(Zhang et al., 2014). Hyperandrogenism is the mark of POCS linked to disorder menstrual cycles, anovulation and /or oligo-ovulation (Kambalachenu et al., 2013). POCS is frequently connected with components of metabolic syndrome, such as, insulin resistance, dyslipidemia, obesity, type 2 diabetes mellitus (T2DM) and long -term cardiovascular complications(Moran et al., 2010 and Cupistiet al. 2008)

Adiponectin is a cytokine secreted from white adipose tissue. It has insulin sensitizing properties as well as antiinflammatory roles (Ghoshal, and Bhattacharyya , 2015).Adiponectin is encoded by a gene located on chromosome 3q27. It has three exons and two introns. The most common variant of exon 2 of adiponectin gene is the rs2241766T $>\mathrm{G}$ polymorphism. It has been illustrated to be associated withthe levels of serum adiponectin, insulin sensitivity, obesity, and T2DM (Han et al. 2011).

Together adiponectin andinsulin resistance are essential elements in the development of PCOS. Thus, it is vital to studyif the SNPs in the adiponectin gene plays a critical role in the pathogenesis of POCS (Zhanget al. 2008).

A number of recent studies have examined the associations between SNPs (rs2241766, and rs1501299) of adiponectin gene and POCS risk.Unfortunately, the results are inconclusive (Panidiset al., 2004,Xitaet al., 2005, and Zhanget al., 2012).
Accordingly, the current study was directed to verify the possible effect of the SNP (rs2241766T $>$ G) in the adiponectin gene among Iraqi woman with POCS. Such attempts are essential to better understand the role of adiponectin gene polymorphism in the development of POCS, and their impact on serum adiponectin levels, and HOMA-IR in Iraqi women with PCOS.

\section{Subject and Methods}

The case -control design study was performed on 120 Iraqi women [age range 15-38, age mean (SD) 21.9 (5.8)]. The woman had a body mass index greater than $26 \mathrm{Kg} / \mathrm{m}^{2}$, and who had not taken hormonal therapy for $>3$ month were recruited in this study. Among them, 60 women with PCOS, while the other 60 were the control group. Who attended the infertility center at Al-Sader Medical City, Najaf, Iraq. A group of woman diagnosed PCOS based on NIH diagnostic criteria, and a group of 60 woman without any history of infertility and clinical signs of hyperandrogenism was included as controls.

For each subject an information on their age, reproductive history, menarche, hirsutism, and blood sample were collected after obtaining written consent. The research contributes undertook basic physical examinations that involved measurement of weight, height, and waist circumferences.

Five milliliters of blood were taken from all patients after 12 hours fasting, put in aliquots into two tubes. The first was analyzed for serum glucose, lipid profile, insulin and adiponectin levels. The second was used for extraction of 


\section{International Journal of Science and Research (IJSR) \\ ISSN (Online): 2319-7064}

Index Copernicus Value (2013): 6.14 | Impact Factor (2015): 6.391

DNA. An enzymatic colorimetric methods were used for determination of serum triglycerides (TG)high-density lipoprotein cholesterol (HDL-C), and total cholesterol (TC). While, Low-density lipoprotein cholesterol (LDL-C) was calculated using Friedwald's formula (Friedewald et al.1972). Serum insulin was determined by ELISA Kit (DRG Instruments GmbH, Germany). Adiponectin was quantified using an ELISA kit (RayBiotech, Inc, USA).

\section{Genotyping:}

Genomic DNA was obtained from peripheral blood specimensby ReliaPrep ${ }^{\mathrm{TM}}$ Blood gDNA Miniprep kit (Promega).

Genotyping of rs2241766T $>\mathrm{G}$ adiponectin gene polymorphism was carried out by amplification of extracting DNA.Primers were: Forward 5'GCAGCTCCTAGAAGTAGACTCTGCTG-3', Reveres:
5'-GGAGGTCTGTGATGAAAGAGGCC-3

et al.2012).Polymerase chain reaction was achieved in a total volume $(20 \mu \mathrm{l}) \mathrm{PCR}$-mixture containing $100 \mathrm{ng} / \mu \mathrm{l}$ template DNA, $1 \mu \mathrm{l}$ (10pmole primer) of each primer, $5 \mu$ l Accpower PCR PreMix. The PCR products were analyzed on $2 \%$ agarose gel electrophoresis to evaluate the overall amplification efficiency. The amplification product was restricted bya SmaI enzyme (Bioword, USA) at $25 \mathrm{C}^{0}$ for 4 hours. The reaction mixture contained the PCR products $(10 \mu 1)$, SmaI $(0.3 \mu 1,10 \mathrm{U} / \mu \mathrm{l})$, buffer $(2 \mu \mathrm{l})$ and nuclease free water $(8 \mu 1)$. The digestion products were resolved on $3 \%$ agarose gel electrophoresis, then viewed using gel documentation system. Uncut product (TT) appeared with a band of $372 \mathrm{bp}$. Products of the heterozygote (TG) genotype exhibited 3 bands of 372,209 , and $163 \mathrm{bp}$ and those with homozygote (GG) genotype highlighted 2 bands of 209 and $163 \mathrm{bp}$.

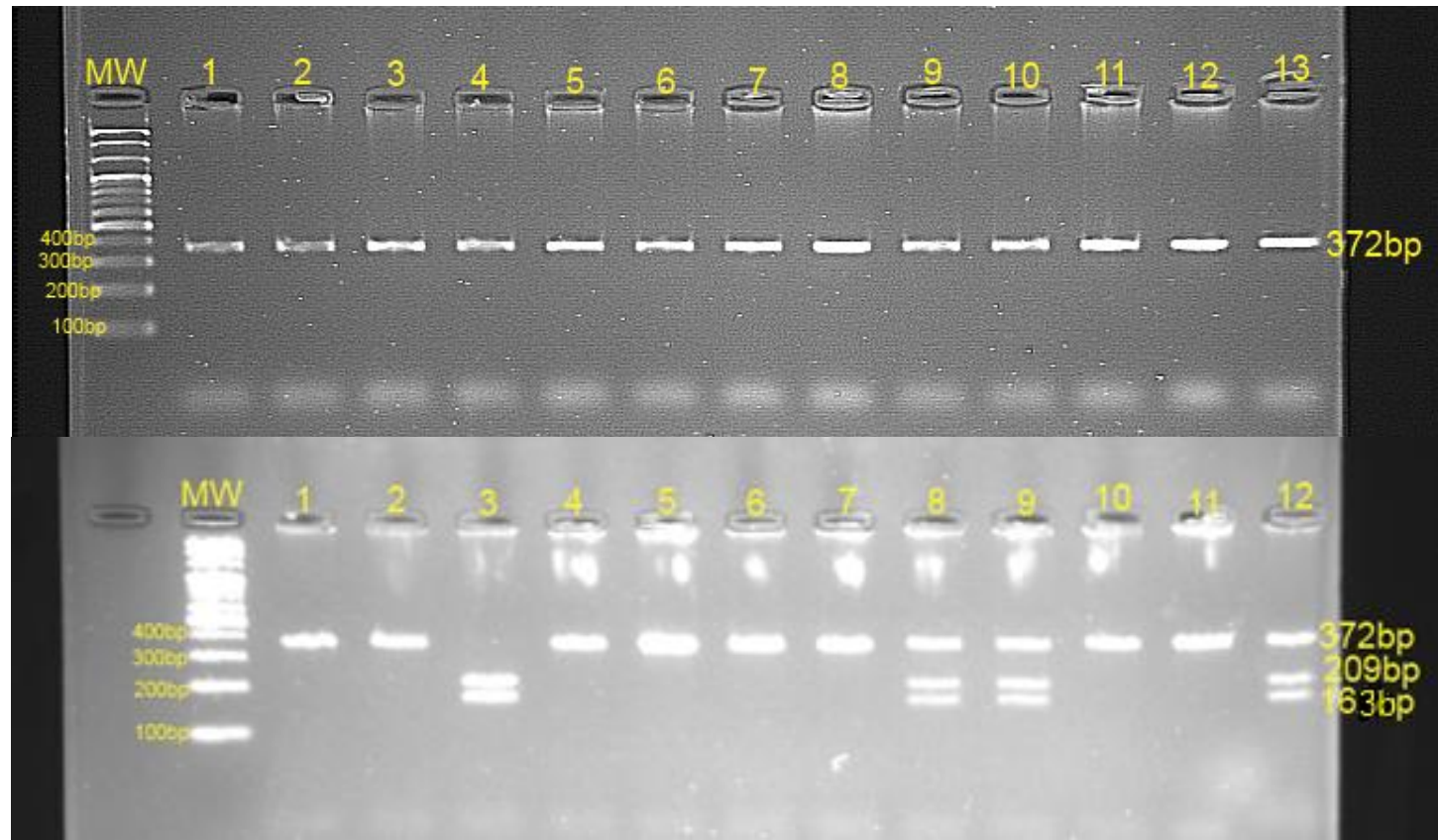

Figure 1: PCR product of SNP (rs2241766T $>$ G) in the adiponectin geneanalyzed by agarose gel electrophoresis.

\section{Statistical analysis}

Biochemical variables are presented descriptively as mean and standard deviation. Significant variances in continuous variables between two groups were confirmed by the ttest,using SPSS version 20.0 software. Genotyping and allele frequencies were compared by using a $\chi^{2}$ test. Odds ratio (OR) and confidence intervals (CI) were also calculated. Multinomial logistic regression of SPSS windows software was used to assess the association of genotypes and allele frequencies with the PCOS group by different inheritance models. HWE was calculated with the use of the online Hardy-Weinberg 2-Allele calculator software - (WWW.had2know.com $)$.

\section{Results}

The clinical and biochemical data of the enrolled women were stated in Table1. Significant difference in Waist circumferences, fasting insulin, HOMA-IR, and serum adiponectin levels were found in POCS group with respects to those of a healthy control group.

Table 1: Clinical and Biochemical data of study participants

\begin{tabular}{|c|c|c|c|}
\hline & $\begin{array}{c}P C O S \\
(N o=60)\end{array}$ & $\begin{array}{l}\text { Controls } \\
\mathrm{NO}=60)\end{array}$ & \multirow[t]{2}{*}{$\begin{array}{c}P \\
\text { (Value) }\end{array}$} \\
\hline & Mean \pm SD & Mean \pm SD & \\
\hline Age (year) & $27.59 \pm 4.63$ & $28.14 \pm 3.36$ & N.S. \\
\hline $\mathrm{BMI}\left(\mathrm{Kg} / \mathrm{m}^{2}\right)$ & $27.56 \pm 2.5$ & $26.73 \pm 3.58$ & N.S. \\
\hline WC (cm) & $0.89 \pm 0.20$ & $0.78 \pm 0.13$ & $<0.001$ \\
\hline Fasting glucose $(\mathrm{mmol} / \mathrm{L})$ & $5.02 \pm 0.5$ & $4.89 \pm 1.02$ & N.S. \\
\hline Fasting insulin $(\mu \mathrm{U} / \mathrm{L})$ & $26.92 \pm 17.79$ & $12.62 \pm 9,87$ & $<0.001$ \\
\hline HOMA-IR & $3.89 \pm 2.3$ & $1.39 \pm 0.5$ & 0.005 \\
\hline TC (mmol/L) & $5.42 \pm 1.51$ & $5.46 \pm 1.65$ & N.S. \\
\hline HDL-c (mmol/L) & $1.34 \pm 0.47$ & $1.43 \pm 0.42$ & N.S. \\
\hline LDL-c (mmol/L) & $2.94 \pm 0.98$ & $3.014 \pm 1.10$ & N.S. \\
\hline TG (mmol/L) & $1.53 \pm 1.98$ & $1.46 \pm 0.517$ & N.S. \\
\hline sAdiponectin $(\mu \mathrm{g} / \mathrm{ml})$ & $6.45 \pm 3.34$ & $9.43 \pm 2.75$ & $<0.001$ \\
\hline
\end{tabular}

No:number.BMI: body mass index, WC: Waist

circumference,, and sAdiponectin: serum Adiponectin

\section{Volume 5 Issue 4, April 2016}




\section{International Journal of Science and Research (IJSR) \\ ISSN (Online): 2319-7064 \\ Index Copernicus Value (2013): 6.14 | Impact Factor (2015): 6.391}

The genotype pattern of patients with PCOS demonstrated frequencies of $51.67 \%, 45 \%$, and $3.33 \%$ for those of homozygous (TT), heterozygous (TG), andhomozygotes (GG) respectively. Healthy control groups exhibited frequencies of $61.67 \%, 36.67 \%$, and $2.242 \%$ for those of homozygous (TT), heterozygous (TG), and homozygotes (GG) respectively. The minor allele frequency of the $T$ and $\mathrm{G}$ in PCOS group was indicated to be $0.742 \%$ and $0.258 \%$, respectively, and $83.334 \%, 16.66 \%$, in the control group respectively. Distribution of genotypes and alleles were not differed significantly between PCOS and control participants. Additionally, genotype results of the selected SNP in the adiponectin gene were in Hardy-Weinberg equilibrium (Table2).
Table 2: Hardy -Weinberg equilibrium (HWE) deviation and allele Frequency of SNP (rs2241766T $>$ G) in the adiponectin gene

\begin{tabular}{|c|c|c|c|c|}
\hline \multirow{2}{*}{} & \multicolumn{3}{|c|}{ Genotyping number/ frequency (\%) } & P \\
\cline { 2 - 3 } & TT & TG & GG & Value \\
\hline PCOS (60) & $31 / 51.67$ & $27 / 45.00$ & $2 / 3.33$ & 0.177 \\
\hline Control (60) & $37 / 61.67$ & $22 / 36.67$ & $1 / 2.242$ & 0.259 \\
\hline & Allele frequency (\%) & \multicolumn{1}{c}{} \\
\cline { 2 - 3 } & T & G & \multicolumn{1}{c}{} \\
\hline PCOS & 0.742 & 0.258 & \multicolumn{1}{|c}{} \\
\hline Control & 0.8051 & 0.195 & \multicolumn{1}{|c}{} \\
\hline
\end{tabular}

When various models of inheritance were considered, unfortunately the difference among the two groups remained insignificant (Table4). No significant difference was observed in the allele frequency of PCOS patients with respect to those in the control group $(\mathrm{OR}=1.333,95 \% \mathrm{CI}$ : 0.564-3.155, $\mathrm{P}=0$. 513).

Table3: Genotyping and allelic results of rs2241766 T>G in the adiponectin gene of PCOS and control groups in association to different inherited models.

\begin{tabular}{|c|c|c|c|c|c|}
\hline \multirow{2}{*}{ Model } & \multirow{2}{*}{ Genotype } & \multicolumn{2}{|c|}{ Frequency\% } & \multirow{2}{*}{$\begin{array}{c}\text { OR } \\
(95 \% \mathrm{CI})\end{array}$} & \multirow{2}{*}{$\begin{array}{c}P \\
\text { (Value) }\end{array}$} \\
\hline & & $P C O S$ & Control & & \\
\hline \multirow{3}{*}{ Codominant } & TT & 31 & 37 & 1.00 & \multirow{3}{*}{0.201} \\
\hline & TG & 27 & 22 & $1.465(0.700-3.06)$ & \\
\hline & GG & 2 & 1 & $2.387(0.207-27.593)$ & \\
\hline \multirow{2}{*}{ Dominant } & TT & 31 & 37 & 1.00 & \multirow{2}{*}{0.143} \\
\hline & TG+GG & 29 & 23 & $0.582(0.280-1.20)$ & \\
\hline \multirow{2}{*}{ Recessive } & TT+TG & 58 & 59 & 1.00 & \multirow{2}{*}{0.567} \\
\hline & GG & 2 & 1 & $2.035(0.179-23.056)$ & \\
\hline Allele & G & 15 & 12 & $1.333(0.564-3.155)$ & 0.513 \\
\hline
\end{tabular}

Biochemical characteristics of the patients with PCOS were analyzed with respect to the dominant model (TT vs TG+GG). With regard to the selected SNP (rs2241766T $>\mathrm{G}$ ), there were no significant differences in a number of women, BMI, age, and fasting blood glucose between the different genotypes. Also, lipid profile were similar. Conversely, in PCOS women with the (TG+GG) genotype compared with those with the TT genotype, insulin concentrations, and HOMA-IR were significantly greater.

Table 4: Clinical and metabolic characteristic in PCOS women under the dominant model.

\begin{tabular}{|c|c|c|c|}
\hline $\begin{array}{c}\text { Adiponectin } \\
\text { (rs2241766T }>\mathrm{G})\end{array}$ & TT & TG+GG & $\begin{array}{c}\text { P } \\
\text { (Value) }\end{array}$ \\
\hline Number of woman & 31 & 29 & N.S. \\
\hline BMI $\left(\mathrm{Kg} / \mathrm{m}^{2}\right)$ & $27.52 \pm 3.86$ & $28.13 \pm 2.35$ & N.S. \\
\hline Age $($ years $)$ & $26.97 \pm 5.23$ & $28.34 \pm 3.81$ & N.S. \\
\hline Fasting glucose $(\mathrm{mg} / \mathrm{dl})$ & $4.87 \pm 0.97$ & $5.53 \pm 0.24$ & N.S. \\
\hline Fasting insulin $(\mu \mathrm{U} / \mathrm{ml})$ & $26.92 \pm 17.79$ & $31.38 \pm 9.75$ & 0.0433 \\
\hline HOMA-IR & $3.89 \pm 2.30$ & $5.48 \pm 2.56$ & $<0.001$ \\
\hline TC $(\mathrm{mmol} / \mathrm{L})$ & $4.93 \pm 2.31$ & $5.61 \pm 1.97$ & N.S. \\
\hline HDL-c $(\mathrm{mmol} / \mathrm{L})$ & $2.16 \pm 0.54$ & $1.32 \pm 0.98$ & N.S. \\
\hline LDL-c $(\mathrm{mmol} / \mathrm{L})$ & $3.1 \pm 0.58$ & $2.65 \pm 1.09$ & N.S. \\
\hline TG $(\mathrm{mmol} / \mathrm{L})$ & $1.87 \pm 2.40$ & $1.73 \pm 1.79$ & N.S. \\
\hline sAdiponectin $(\mu \mathrm{g} / \mathrm{ml})$ & $7.01 \pm 2.17$ & $5.75 \pm 4.34$ & N.S. \\
\hline
\end{tabular}

\section{Discussion}

Polycystic ovary syndrome is complex multigenic and heteroplasimic disease, and result from the interaction between various susceptibility genes with each other to and environmental factors (Zhanget al., 2014). Therefore, the relationship between single nucleotide polymorphisms and PCOS has become a subject of interest. Most attention has been given to adipocyte secretory proteins (adipokines), particularly focus on adiponectin (Trujilloet al. 2005). Hypoadiponectinemia is closelylinked tometabolic syndrome,insulin resistance, and diabetes(Mazloomiet al., 2012, and Kernet al., 2003). Women with PCOS have an amplified incidence of metabolic syndrome. Insulin resistance with profitable hyperinsulinaemia and hypoadiponectinema free of obesity has been stated in PCOS (Homburg1996).

It has been recommended that decline in serum adiponectin levels linked with obesity, the development of insulin resistance, and metabolic syndrome (Zhanget al. 2008).In the present study, we determined the levels of serum adiponectin in women with PCOS and age and BMI matched healthy women. The plasma adiponectin concentration is lower in PCOS group. Accordingly, the data proposed a critical role of hypoadiponectinemia in pathophysiology of the insulin action and lipid abnormality of PCOS.

Adiponectin can reduce body weight, improve glucose metabolism and lipid profile. In the other side, adiponectin, represents a major link between obesity and reproduction(Ghoshal \& Bhatt 2015). Higher adiponectin levels are connected with enhanced menstrual function and well products in helping reproductive cycles(Allawayet al., 2016)

Numerous single nucleotide polymorphisms (SNPs) located in the adiponectin gene have been related to circulating

\section{Volume 5 Issue 4, April 2016}




\section{International Journal of Science and Research (IJSR) \\ ISSN (Online): 2319-7064}

Index Copernicus Value (2013): 6.14 | Impact Factor (2015): 6.391

adiponectin levels (Zhanget al. 2015). Most research has focused on the $\mathrm{rs} 2241766 \mathrm{G}<\mathrm{T}$, and the results are conflicting(Lin et al. 2012).

In Iraq, this is the first research that evaluated the association between the $\mathrm{rs} 2241766>\mathrm{G}$ polymorphisms of adiponectin gene and PCOS. In the current work,no significant difference in the distribution among women with PCOS group and a control group.

The results of the present study are agreeing with those of Demiric et al. 2010, Li et al. 2011, Sanl Millan et al. 2004, Escobar et al. 2006. And Fahimeh et al. 2013.While, Zhang et al. 2008 stated that it was significant relation with PCOS in Han Chinese women. Haap et al. 2014 pointed that $\mathrm{rs} 2241766 \mathrm{G}>\mathrm{T}$ polymorphism has a higher prevalence in PCOS women compared with control subjects.

It is essential considered some limitations of the current study. First, the study has a case-control design. It would be limited by links SNPs in candidate genes with disease, and unable to point the disease that may arise on account of population stratification by ethnicity or environmental factors. Second, only one SNPs within the adiponectin gene were evaluated for its relation with PCOS, and not all of the SNPs stated in the literature. Third, the disparity between our results and assumptions may be due to the relatively small number of patient and control women.

However, our results highlight that the selected polymorphism in the adiponectin gene have approximately similar distribution of the allelic variant in the PCOS and the control group.Furthermore, carriers of the TG and GG genotype were more hyperinsulinemia, and insulin resistance compared with the PCOS women with the TT genotype.In addition, PCOS patients with TG and GG had low adiponectin levels than those with TT genotype, although the difference was not significant, may be as a result of the small sample size of PCOS women.

\section{Conclusion}

The current study point out that the selected SNP $(\mathrm{rs} 2241766 \mathrm{~T}>\mathrm{G})$ in adiponectin gene is not related to PCOS in Iraqi women. Nevertheless, the selected polymorphism was found to be associated with insulin levels, and HOMA-IR among Iraqi women with PCOS, and to impact adiponectin secretion. Further research with a greater sample size, and more SNPs in adiponectin gene polymorphisms are wanting to confirm these results.

\section{References}

[1] Allaway H., Southmayd E., De Souza M. The physiology functional hypothalamic amenorrhea associated with the energy of deficiency in exercising women and in women anorexia nervosa. Horm Mol Biol Clin Investig. 2016;25(2):91-119.

[2] Berg A., and Scherer P. Adipose tissue, inflammation, and cardiovascular disease. Circulation Research. 2005; 96(9)939-949.
[3] Cupisti S, Kajaia N, Dittrich R, et al. Body mass index and ovarian function are associated with endocrine and metabolic abnormalities in women with hyperandrogenic syndrome. Eur J Endocrinol 2008;158:711-9.

[4] Demirci H, Yilmaz M, Ergun MA, Yurtcu E, Bukan N, Ayvaz G. Frequency ofadiponectin gene polymorphisms in polycystic ovary syndrome and the association with serum adiponectin, androgen levels, insulin resistance and clinical parameters. Gynecol Endocrinol 2010;26:348-55.

[5] Escobar-Morreale HF, Villuendas G, Botella-Carretero JI, Alvarez Blasco F, Sanch_on R, Luque-Ramírez M, et al. Adiponectin and Resistin in PCOS: a clinical, biochemical and molecular genetic study. Hum Reprod 2006;21: 2257-65.

[6] Friedewald W., Levy R., \& Fredrickson D. Estimation of the Concentration of low-density lipoprotein cholesterol in plasma, without use of the preparative ultracentrifuge. Clinical chemistry. 1972;18: 499 -502.

[7] Ghoshal K., and Bhattacharyya M. Adiponectin: Probe of the molecular paradigm associating diabetes and obesity. World J Diabetes. 2015 February 15; 6 (1): 151-166.

[8] Ghoshal K., and Bhattacharyya M. Adiponectin: Probe of the molecular paradigm associating diabetes and obesity. World J Diabetes. 2015; 6(1): 151-166.

[9] Han L., Wu Q., Jiao M., Hao Y., Liang L., Gao L., Legge D., Quan H, Zhao M., Ning N, Kang Z \& Sun H. Associations between single-nucleotide polymorphisms $\quad(+45 \mathrm{~T}>\mathrm{G}, \quad+276 \mathrm{G}>\mathrm{T}, \quad-11377 \mathrm{C}>\mathrm{G}$, $-11391 \mathrm{G}>\mathrm{A}$ ) of adiponectin gene and type 2 diabetes mellitus: a systematic review and metaanalysis.Diabetologia .2011; 54:2303-2314.

[10] Homburg R., Polycystic ovary syndrome-from gynaecological curiosity to multisystem endocrinopathy," Human Reproduction, vol. 11, no. 1, pp. 29-39, 1996.

[11] Jang Y, Lee JH, Chae JS, Kim OY, Koh SJ, Kim JY, Cho H, Lee JE, Ordovas JM. Association of the 276G3T polymorphism of the adiponectin gene with cardiovascular disease risk factors in nondiabetic Korean. Am J Clin Nutr.2005; 82:760 -7.

[12] Kambalachenu H., Paul S., Nellepalli S., and Venkatachalam P. Study on follicle stimulating hormone receptor gene polymorphisms in south Indian woman with polycystic ovarian syndrome. American Medical Journal 2013; 4 (2): 160-167.

[13] Kern P., Gregorio G., Lu T., Rassouli N., and Ranganathan G., Adiponectin expression from human adipose tissue: relation to obesity, insulin resistance, and tumor necrosis factor- $\alpha$ expression. Diabetes. 2003; 52(7):1779-1785.

[14] Li L, Yun JH, Lee JH, Song S, Choi BC, Baek KH. Association study of $45 \mathrm{G} 15 \mathrm{G}(\mathrm{T} / \mathrm{G})$ and $276(\mathrm{G} / \mathrm{T})$ polymorphisms in the adiponectin gene in patients. Int $\mathrm{J}$ Mol Med 2011;27:283-7.

[15] Li X., Wei D., He H., Zhang J., Wang C., Ma M., Wang B., Yu T., Pan L., Xue F., He H., Xu W. Pan T., Zuo Q., Ulf L, Shan G. Association of the adiponectin gene (ADIPOQ) $+45 \mathrm{~T}>\mathrm{G}$ polymorphism with the metabolic syndrome among Han Chinese in Sichuan province of china. Asia Pac J Cli Nutr.2012; 21(2): 296-301. 


\section{International Journal of Science and Research (IJSR) \\ ISSN (Online): 2319-7064}

Index Copernicus Value (2013): 6.14 | Impact Factor (2015): 6.391

[16] Lin C, Ho C, Liu C, Wen-Yuan L,Chia-Ing L , Chuan-Wei Y, Da-Tian B, Tsai-Chung L, ChengChieh L. Influence of Adiponectin Gene Polymorphisms on Adiponectin Serum Level and Insulin Resistance Index in Taiwanese Metabolic Syndrome Patients. Chinese Journal of Physiology. 2012;55(6): 405-411.

[17] Mazloomi S., Sharifi F.,Hajihosseini R., and Kalantari S. Association between Hypoadiponectinemia and Low SerumConcentrations of Calcium and Vitamin D in Women with Polycystic Ovary Syndrome. ISRN Endocrinology.2012; Article ID 949427, 6 pages.

[18] Moran L., Misso M., Wild R., Norman R. Impaired glucose tolerance, type 2 diabetes and metabolic syndrome in polycystic ovary syndrome: a systematic review and meta-analysis. Hum Reprod Update 2010;16:347-63.

[19] Panidis D, Kourtis A, Kukuvitis A, Farmakiotis D, Xita N, Georgiou I \& Tsatsoulis A. Association of the T45G polymorphism in exon 2 of the adiponectin gene with polycystic ovary syndrome: role of Delta4 androstenedione. Human Reproduction 2004 ;19 :1728-1733.

[20] San Millan JL, Corton M, Villuendas G, Sancho J, Peral B, Escobar- Morreale HF. Association of the polycystic ovary syndrome with genomic variants related to insulin resistance, type 2 diabetes mellitus, and obesity. J Clin Endocrinol Metab 2004;89:26406.

[21] Trujillo M., and Scherer P., - Aliponectin-journey from an adipocyte secretory protein to biomarker of the metabolic syndrome," Journal of Internal Medicine. 2005 ;257 (2): 167-175.

[22] Xita N, Georgiou I, Chatzikyriakidou A, Vounatsou M, Papassotiriou GP, Papassotiriou I \& Tsatsoulis A. Effect of adiponectin gene polymorphisms on circulating adiponectin and insulin resistance indexes in women with polycystic ovary syndrome. Clinical Chemistry 200551 416-423.

[23] Zhang N., Shi Y., Hao C., Gu F., Li Y., Zhao Y., Wang L., and Chen Z. Association of C45G15G $(\mathrm{T} / \mathrm{G})$ and $\mathrm{C} 276(\mathrm{G} / \mathrm{T})$ polymorphisms in the ADIPOQ gene with polycystic ovary syndrome among. European Journal of Endocrinology; 2008; $158255-260$.

[24] Zhang W, Wu X, Ding M, Yu X, Liu G, Shi Y. Casecontrol based study between polymorphisms in the adiponectin gene and polycystic ovary syndrome.Zhonghua $\mathrm{Fu}$ Chan $\mathrm{Ke} \mathrm{Za}$ Zhi. 2015;50(11):825-9.

[25] Zhang W.,Wei D.,Sun X., Li Jing, Yu X.,Shi Y.,and Chen J. Family-based analysis of adiponectin gene polymorphisms in Chinese Hastic on polycystic ovary syndrome. Fertility and Seritilty 2014;101:1419-1423. 